Fanum

Sociológico

\section{Forum Sociológico}

Série II

23 | 2013

Número 23

\title{
Cidadãos, técnicos e políticos: do que falamos, quando falamos de participação pública?
}

\section{Cecília Delgado}

\section{Q OpenEdition}

1 Journals

\section{Edição electrónica}

URL: https://journals.openedition.org/sociologico/834

DOI: 10.4000/sociologico.834

ISSN: 2182-7427

\section{Editora}

CICS.NOVA - Centro Interdisciplinar de Ciências Sociais da Universidade Nova de Lisboa

\section{Edição impressa}

Data de publição: 1 novembro 2013

Paginação: 69-76

ISSN: 0872-8380

\section{Refêrencia eletrónica}

Cecília Delgado, «Cidadãos, técnicos e políticos: do que falamos, quando falamos de participação pública?», Forum Sociológico [Online], 23 | 2013, posto online no dia 01 janeiro 2014, consultado o 30 março 2022. URL: http://journals.openedition.org/sociologico/834 ; DOI: https://doi.org/10.4000/ sociologico.834

Este documento foi criado de forma automática no dia 30 março 2022.

(C) CICS.NOVA 


\title{
Cidadãos, técnicos e políticos: do que falamos, quando falamos de participação pública?
}

\author{
Cecília Delgado
}

\section{A importância da participação}

1 As Nações Unidas enfatizam a importância da participação como uma forma de promover a democracia e fortalecer o estado de direito. Nos objetivos de desenvolvimento do milénio (2000-2015) proclama-se a necessidade de trabalhar coletivamente para conseguir que os processos políticos sejam mais abrangentes, de modo a

permitirem a participação efetiva de todos os cidadãos, em todos os países, e assegurar a liberdade dos meios de comunicação para cumprirem a sua função, i.e., o direito de o público ter acesso à informação.

2 As vantagens da participação pública são reconhecidas. De acordo com Petts (2000), alargam o leque de questões a analisar em comparação com os pressupostos ideologicamente formatados que os técnicos introduzem. Gonçalves (2000) reforça esta posição ao afirmar que as pessoas são expostas a outras fontes de informação para além das fontes científicas e técnicas, e são capazes de assimilar e ponderar a informação de diferentes origens, o que contribui para o enriquecimento das soluções propostas. Compreensível, num sistema científico que se especializou até ao "limite" da especialização, a ignorância acerca de um domínio específico da ciência é quase tão grande entre cientistas que trabalham noutra área como entre os leigos (Felt, 2000). A experiência demonstra que o envolvimento dos atores em processos de intervenção urbana, mediante uma partilha de objetivos e soluções, é um fator decisivo para o sucesso dessas operações, não só a curto prazo, mas também porque assegura a manutenção dos resultados ao longo do tempo, decorrente de uma maior satisfação e identificação dos destinatários (Alves, 2001). 
O estudo "Participation, Leaderships and Urban Sustainability" (2004), realizado pelo Centro de Investigação das Cidades da Universidade de Bristol, comparou o envolvimento comunitário em nove países da União Europeia e o modo como esse fator contribui para a melhoria das decisões políticas no âmbito do desenho da cidade. Os casos estudados confirmaram que o envolvimento comunitário transversal, ao nível das associações locais, das universidades, dos grupos com interesses específicos, da sociedade civil, etc., é um fator relevante na definição das políticas de ordenamento urbano nomeadamente porque: ${ }^{1}$ ) garante que o poder institucional identifica com maior acuidade as necessidades e preocupações locais; ${ }^{2}$ ) contribui para a melhoria da qualidade das decisões políticas ao permitir identificar alternativas que muitas das vezes escapam ao setor institucional e técnico; ${ }^{3}$ ) possibilita o conhecimento público das tomadas de posição governamental; 4) assegura a legitimidade das decisões e permite um melhor acompanhamento da implementação dos processos; 5) mobiliza recursos necessários à boa execução dos objetivos políticos. Finalmente, o envolvimento comunitário na gestão territorial reduz a instabilidade decorrente das alterações na liderança política.

4 No seu artigo "Reframing Public Participation: Strategies for the $21^{\text {st }}$ Century", Judith Innes e David Booher (2004) enunciam cinco pressupostos que justificam a necessidade da participação pública. As razões corroboram as conclusões do estudo anteriormente referido. Reconhece-se a necessidade de quem decide compreender as preferências dos cidadãos de modo a incorporá-las nas suas opções e melhorar a tomada de decisão através da informação local dos cidadãos. Simultaneamente, introduz-se o princípio da imparcialidade como meio de acautelar que as decisões sejam tomadas com equidade, legitimidade e respeito pelos cidadãos. Por outro lado, alude-se à participação como um meio de validar e legitimar decisões políticas. Por último, assume-se a necessidade legal de o fazer - porque a legislação assim o obriga.

Diversos estudos apontam ainda a participação como um meio de aumentar a satisfação dos cidadãos (Ferreira, 2003; Guerra, 2006; Healey, 2006; Ascher, 2010), na medida em que existe uma correspondência entre os resultados e as aspirações destes. Em sentido inverso, intervenções onde os pressupostos de diálogo e transparência não estejam presentes podem gerar um clima de controvérsia e insatisfação, aumentando as clivagens sociais e limitando os pressupostos democráticos. Em síntese, é consensual que a participação pública é um importante meio de intercâmbio de informação, de salvaguarda de direitos, de legitimação de decisões, evita contestações e é também uma obrigação face aos princípios democráticos vigentes. Em síntese, defende-se uma participação útil, tanto socialmente como politicamente, mas omite-se que o conceito de participação, conforme defendido por Arnstein (1969), implica uma posição que tende a nivelar o poder entre quem decide e os cidadãos, posição da qual a maioria dos decisores não está disposta a abdicar.

\section{Os dilemas das participação em Portugal}

6 As relações entre cidadania e equidade prevalecentes em Portugal são complexas e diferenciadas, sendo indiscutível que o sentimento de iniquidade social se relaciona com a falta de recursos para participar na vida cívica, levando a que a grande maioria dos Portugueses se sinta profundamente "distante do poder", afirmam Cabral et al. (2008). Mattoso (2008) defende que em Portugal o Estado desempenha um papel intenso 
de regulação social, mas permanece uma grande distância entre representantes e representados. É ainda um Estado que tenta imitar os padrões de atuação dos Estados e das políticas mais desenvolvidos, o que se reflete numa legislação frequentemente muito progressista, sem que os agentes políticos interiorizem esses padrões nas orientações operacionais e na prática política. Já em 1997 Lourenço et al. sublinhavam a ausência de participação em Portugal mencionando o excessivo caráter técnico dos documentos disponibilizados para discussão, o facto de a participação pública ser motivada fundamentalmente pelos interesses particulares em detrimento dos interesses difusos, a fraca ressonância da participação pública nas decisões finais, as debilidades técnicas das autarquias à mercê do Poder Central, a cientificação das decisões e a falta de informação científica adequada ao nível de conhecimentos do cidadão em geral.

7 Estabelecidas as causas que poderão justificar o nível reduzido de participação em Portugal, é preciso perceber que estas questões não são exclusivamente portuguesas mas um fenómeno igualmente frequente noutros países. Os métodos de participação pública tradicionais não funcionam quando não criam informação significativa que permita e facilite às entidades fazer a diferenciação na tomada de decisão ou não garantam aos cidadãos que as suas questões sejam consideradas nas decisões $a$ posteriori, afirmam Innes e Booher (2000). Sobrevém ainda o fenómeno NIMBY (not in my backyard syndrome) ou a constatação da diferença de prioridades entre os técnicos e o público em geral, muitas vezes usadas pelos primeiros para desqualificar a posição dos cidadãos, rotulando-a como egoísta, pouco informada, meramente emocional ou irracional (Lima, 2000). Esquece-se que o planeamento urbano é um processo dinâmico e interativo, feito por todos e para todos, sujeito a revisão permanente e pressupondo transparência e vontade, simultaneamente política e da sociedade civil.

\section{A questão}

8 Raramente são estabelecidas comparações entre os diversos grupos que compõem a pirâmide de decisão hierárquica: na base - os cidadãos que vivem nas cidades, com poderes limitados de intervenção; no meio da pirâmide - os técnicos que planeiam as cidades, e no topo - os políticos que decidem as políticas urbanas. Parte-se do pressuposto de que uma cidade mais equitativa é uma cidade pensada a partir da perspetiva de todos e todas. $\mathrm{E}$ da hipótese de que essa perspetiva varia entre os grupos mencionados. Defende-se que a participação pública é o instrumento privilegiado para construir a visão coletiva da cidade - é pois preciso perceber do que falamos, quando falamos de participação pública?

\section{Estudo de caso: seleção da amostra}

A amostra deste estudo é composta por cidadãos, políticos e técnicos, envolvidos no Programa Polis em Vila Nova de Gaia1 (2000-2007). A cidade de Vila Nova de Gaia situase na região norte de Portugal, na margem esquerda do rio Douro, o qual estabelece a fronteira natural com a cidade do Porto.

Para a seleção da nossa amostra existiam três possibilidades: 1) estudar a totalidade da população; 2) estudar uma amostra representativa da população; 3) estudar 
componentes não necessariamente representativas, mas características da população. Optou-se por estudar grupos, não necessariamente representativos, mas cujas características fossem relevantes para a nossa hipótese. De acordo com Quivy e Campenhoudt (2005), esta é a fórmula mais frequente nas Ciências Sociais - o investigador ao diversificar os perfis dos inquiridos chegará inevitavelmente ao momento de saturação em que, por mais entrevistas que faça, dificilmente alcançará informação adicional relevante.

11 Em representação do grupo de cidadãos, inquiriu-se um grupo de 100 alunos2 que frequentava o ano que precede a entrada na universidade. Uma parte significativa dos alunos (66\%) situava-se na faixa etária dos 17 anos, os alunos com 16 anos representavam $21 \%$ da amostra e a percentagem de alunos com idade entre os 18 e os 20 anos de idade representava $13 \%$.

Relativamente ao grupo dos políticos e técnicos, inquiriram-se todos os técnicos e políticos envolvidos no Programa3. 0 universo total da população perfez 81 indivíduos. Destes 26 foram contabilizados como políticos, face à função desempenhada no Programa Polis (ver Tabela 1).

Tabela 1 㡠 Composição da amostra por género e grupos de decisão

\begin{tabular}{|c|c|c|c|c|c|}
\hline & $m+M=D$ & $M+M-$ & De reletive Dop & N. - Menmen - & k.Mulaneres - \\
\hline Rolite & 28 & 21 & 90 & 22 & 0 \\
\hline Tealk & 25 & 47 & 85 & 29 & 18 \\
\hline Clidad & $100 \%$ & 100 & 100 & 40 & 60 \\
\hline
\end{tabular}

* O grupo de políticos e técnicos representa a população total. Os cidadãos uma amostra.

13 No grupo dos políticos incluíram-se todos os elementos do Conselho de Administração da GaiaPolis, ou seja, os representantes da CCDRN, da Autarquia de Vila Nova de Gaia e da Parque Expo; os Presidentes das quatro Juntas de Freguesia abrangidas pela área de intervenção; o Coordenador Nacional do Programa Polis; o Coordenador da Parque Expo para o Programa Polis; os dois Diretores Gerais da DGOTDU; os vereadores da Câmara Municipal de Vila Nova de Gaia. Admite-se que estas categorias possam não ser rigorosamente estanques e exclusivas, na medida em que pontualmente decisões técnicas foram da responsabilidade de elementos do grupo dos políticos, tendo o inverso também ocorrido. Considerada a similitude das respostas entre estes dois grupos (ver resultados), este fator não nos parece ter expressão nas conclusões.

14 O grupo dos 55 técnicos englobou as equipas dos quatro Planos de Pormenor, os arquitetos autores dos projetos elaborados no âmbito do Programa Polis e os contratados pela GaiaPolis, os funcionários da CCDRN e da Câmara Municipal de Vila Nova de Gaia, a equipa da GaiaPolis e os arquitetos responsáveis pelos projetos dos principias lotes privados.

15 A faixa etária dos técnicos e políticos variou entre os 28 e os 68 anos de idade. Destaque para a ausência de mulheres no grupo de políticos. O sexo feminino representava $38 \%$ da amostra, sendo a faixa etária média inferior à dos homens.

16 A formação académica entre políticos e técnicos era igual ou superior à licenciatura, no entanto registaram-se três casos de formação inferior à licenciatura no grupo dos políticos. A área académica predominante nos técnicos era a arquitetura $(79 \%)$ e nos políticos a engenharia ( $43 \%$ ). A distribuição por área de residência era a seguinte: Porto 
(41 \%); Vila Nova de Gaia (29\%); Lisboa (18 \%); outras cidades (15\%). No conjunto, $82 \%$ dos inquiridos residiam na Área Metropolitana do Porto - AMP, e $18 \%$ fora da AMP. Todas as mulheres viviam na Área Metropolitana do Porto, em contraste $24 \%$ dos homens viviam fora da Área Metropolitana do Porto.

\section{Abordagem metodológica}

17 Na formulação do inquérito e da entrevista consideraram-se as observações resultantes do pré-teste realizado no contexto de vizinhança. Optou-se por utilizar diferentes abordagens linguísticas, de onde as diferentes formatações: (1) inquérito aos cidadãos; (2) entrevista aos técnicos e políticos. Utilizou-se uma entrevista com uma proporção idêntica de perguntas abertas e semifechadas.

Nos dois questionários foram usadas perguntas-filtro. No inquérito fornecido aos cidadãos foi usada a cidade de Vila Nova de $\mathrm{Gaia}^{4}$, nas entrevistas administradas aos políticos e técnicos o Programa Polis em Vila Nova de Gaia.

19 As amostras foram recolhidas entre Outubro de 2007 e Junho de 2008. Aplicaram-se dois tipos de abordagens metodológicas: a técnica quantitativa; e a técnica qualitativa na justificação das respostas. Sempre que possível foram realizados testes estatísticos, nomeadamente o $\mathrm{Qui}^{2}$. Considerou-se estar perante uma correlação estatisticamente significativa sempre que $p \leq 0,050$. Como ressalva metodológica, sublinhe-se que os resultados obtidos são apenas válidos para a amostra estudada, não obstante levantarem hipóteses a aprofundar em trabalhos futuros.

\section{Resultados}

\section{Se é importante participar. a visão dos técnicos e políticos}

Questionados sobe a importância da participação pública para a tomada de decisões no âmbito do planeamento urbanístico de uma cidade $99 \%$ dos inquiridos responderam ser importante participar. Defende-se a participação pública como um instrumento privilegiado de mediação entre os decisores e as populações 5 . São os técnicos $(57,5 \%)$ e os homens (60\%) quem mais justifica deste modo a importância da participação pública, e menos os políticos (48,5\%) e as mulheres (40\%). A participação é igualmente assumida pelos técnicos como algo "didático", que informa o processo: "os cidadãos, como utilizadores do espaço, (...) podem lançar motes para as estratégias" (T-M) ${ }^{6}$. A participação é ainda reconhecida como um meio para reduzir potenciais conflitos: "a única forma de as ações (...) não serem curto-circuitadas e serem aceites, desenvolvidas e corrigidas" (T-M). Por fim, a participação pública é importante mas balizada, ou seja: "é importante que os cidadãos participem, sejam ouvidos, critiquem, etc., etc., mas é relativamente importante. A definição da estratégia urbana de uma cidade cabe, em última análise, numa democracia representativa, aos órgãos eleitos" (P-M). Posicionamento assumido por cerca de um terço dos técnicos.

\section{Se é importante participar. a visão dos cidadãos}

A mesma questão colocada ao grupo de cidadãos demonstra que a maioria dos inquiridos assume a importância de participar, sendo de destacar que nenhum dos 
inquiridos admite não ser importante participar. As respostas ${ }^{7}$ baseiam-se no princípio de que, como utilizadores das cidades, os cidadãos tem maior conhecimento das suas necessidades (38 \%). "São os cidadãos que vivem e lidam com os problemas do dia-a-dia, e como tal conhecem bem o que é bom e mau para a sua cidade" (C-M). É também um grupo que possui um entendimento diferente de quem decide: "porque muitas vezes o que os políticos pensam nem sempre é o que as pessoas pensam e querem, e muitas vezes é o público, em geral, que sabe quais as necessidades para a sua cidade e assim ao participarem ativamente poderiam expor as suas ideias e chegar a um consenso" (C-F). Acrescente-se que, ao participarem nas decisões, os cidadãos contribuem para um aumento do sentimento de pertença e identidade territorial, o que favorece "que a cidade reflita os seus gostos e aspirações (...) e não a idealizada pelos arquitetos ou presidentes" (C-F).

22 Não deixa de ser pertinente evocar as razões por que oito inquiridos respondem ser indiferente participar. Destacam-se dois fatores: a tarefa de decidir é uma obrigação de quem foi eleito para o fazer - "as pessoas elegem alguém para tomar essas decisões" (C$\mathrm{M})$, assim sendo: "o planeamento urbanístico deve estar a cargo do Presidente da Câmara" (C-F). Em segundo lugar, o sentimento da inconsistência e desinteresse dos cidadãos nos atos participativos: "nem todas as pessoas têm as mesmas opiniões e podia haver problemas" (C-F), as pessoas têm “(...) mais em que pensar" (C-F). Por géneros, constatamos que a razão a) "utilizadores têm maior conhecimento e outra visão da realidade" é mais feminina do que masculina. Em contraponto, a razão b) "direito e dever em democracia - a cidade é de todos" é uma visão mais masculina do que feminina.

\section{A participação efetiva dos cidadãos}

Sendo reconhecida a importância da participação dos cidadãos na definição da estratégica urbana das cidades, exige-se compreender porque é que essa participação é na prática inexistente. A questão foi colocada aos técnicos e políticos, sem abrangência territorial definida, e referenciada à cidade de Vila Nova de Gaia, para o grupo dos cidadãos. A opção baseou-se na hipótese de que o rigor das respostas dos cidadãos ficaria comprometido se a questão lhes fosse direcionada num âmbito territorial mais abstrato. De facto, os resultados confirmaram o pressuposto - mais de um terço dos cidadãos inquiridos afirma não saber se a participação na sua cidade é suficiente.

\section{A participação efetiva: a visão dos técnicos e políticos}

No grupo dos técnicos e políticos existe unanimidade sobre a não participação pública dos cidadãos. Metade dos inquiridos admite que a participação não existe porque as instâncias competentes não informam ou não estimulam a participação8: "as Câmaras não encorajam, só fazem aquilo que é estritamente legal" (T-M). Por outro lado, "as participações também são viciadas pelos próprios políticos, (...) a maneira como os dados são avançados não permite ver onde é que eles [as populações] têm alguma informação, que dê para debater as questões" (T-M). A falta de cultura cívica e de formação é outra das razões apontadas para a ausência de participação dos cidadãos quase metade dos inquiridos. Uma das evidências deste facto é o recorrente "interesse individual em detrimento do coletivo" (T-M). Mais de metade dos técnicos e das mulheres assume que as instâncias competentes não informam e não estimulam a 
participação. No entanto, quase metade dos homens também partilha dessa opinião. A razão "falta de cultura cívica e de formação da generalidade dos cidadãos" é mais relevante para os políticos.

\section{A participação efetiva: a visão dos cidadãos} justificam reafirmando que a participação dos cidadão é suficiente, quatro não justificam a sua resposta, e dois respondem que as decisões no âmbito do planeamento urbano devem ser realizadas por quem é eleito e/ou por quem tem competência para o 
fazer, o que por conformidade justifica que a participação existente (muita ou pouca, não nos é possível aferir) é suficiente.

\section{O que fazer para aumentar a participação: a versão dos cidadãos}

32 Existe um afastamento dos cidadãos relativamente à causa pública, como se confirma pelo elevado nível de abstencionismo eleitoral, pela reduzida participação nos períodos de discussão dos instrumentos urbanísticos, pela evolução do desinteresse generalizado patente nos resultados do Inquérito Social Europeu comparado para os anos 2002/2004/2006. De onde ser importante encontrar medidas para aumentar a participação dos cidadãos. Questionámos o nosso grupo de cidadãos sobre quais seriam as razões por que as pessoas não participam. ${ }^{12}$

33 A nossa amostra de cidadãos considera que as pessoas não participam mais porque as entidades competentes não fomentam essa participação ${ }^{13}$. Como refere um dos inquiridos: "os superiores [Presidentes de Junta e de Câmara] pensam que sabem mais e pensam que o povo é ignorante e por isso não têm que dar opinião nenhuma" (C-F). Refere outro cidadão que as pessoas não participam "porque, na maioria das vezes, não é solicitada a sua opinião" (C-F).

34 A segunda razão apontada sublinha o imobilismo e desinteresse dos cidadãos: "porque o povo não tem vontade de se meter em decisões políticas" (C-M); "As pessoas conformam-se demasiado com aquilo que têm. As suas casas são o bastante para se preocuparem" (C-F). Em síntese: por um lado, as pessoas não são chamadas e incentivadas a participar (condicionante externa); mas, igualmente, as pessoas não participam por desinteresse (condicionante interna). A primeira razão é referida por metade das inquiridas mulheres, em detrimento de menos de um terço dos homens. Relativamente ao fator desinteresse, constata-se que este é apontado por mais de metade dos homens e apenas por um terço das mulheres.

\section{O que fazer para aumentar a participação: a versão dos técnicos e políticos}

Para os técnicos e políticos, a solução para aumentar a participação ${ }^{14}$ passaria por: "maior transparência, maior divulgação de factos objetivos e seriedade na concretização desses objetivos". Refere um dos inquiridos: "É necessário... momentos muito bem identificados onde as pessoas sejam chamadas a participar. E não a participar porque há uma ou outra notícia no jornal, mas a participar porque há documentos preparados para as pessoas perceberem exatamente quais são as opções em presença, que sejam explicados de uma forma muito simples, com uma antevisão muito realista e, digamos que, neutral, não enfatizando uma opção mas procurando mostrar quais são as alternativas e, com base nesses documentos, em momentos muito próprios, chamar as pessoas a darem essa opinião" (P-M). A segunda razão corresponde ao princípio da descentralização do debate, ou seja, aproximar o debate dos cidadãos, considerando especialmente os mais atingidos pelas decisões em discussão. Como refere um dos inquiridos: "algumas reuniões públicas (...) bastante próximas dos interessados, [onde] há alguma participação porque as pessoas veem as coisas mais como sendo coisas que lhes dizem respeito, há uma relação de proximidade" (P-M). 
36 Recapitulando, as duas razões mais apontadas remetem diretamente para uma ação pró-ativa por parte das entidades competentes, que deveriam "clarificar e divulgar os momentos de debate" e "descentralizar o debate, aproximando-o dos cidadãos".

\section{Síntese - Análise e Discussão}

Os resultados obtidos confirmam o reconhecimento de todos os atores de que a cidade é um fenómeno coletivo, constituída por diferentes grupos, com necessidades, aspirações e visões nem sempre coincidentes. A participação pública é assumida como a ferramenta para compreender essa diversidade. Para os técnicos e políticos, é um instrumento de mediação que lhes permite interagir com as populações. Por outro lado, os cidadãos reconhecem que têm uma visão "diversa" da realidade e assumem a participação como um direito e um dever que lhes pertence numa sociedade democrática. Entendem ainda que a participação os aproxima da sua cidade, aumentando o sentimento de pertença e identidade, fator que igualmente, embora em menor escala, é identificado pelos técnicos e políticos.

A participação só existe se for fomentada e credibilizada. Assume-se que a participação pública é importante face aos cânones da democracia vigente, mas essa participação é seletiva: "não é o Zé da esquina, ele não percebe nada disso" (T-F). No limite a "participação pública" é "apenas" um meio de legitimar decisões (Guerra, 2006) e um instrumento de propaganda e de marketing políticos.

39 Cidadãos, técnicos e políticos concordam que os fóruns competentes não incentivam ou fomentam a participação. Este é, parece-nos, um dos pontos fundamentais da discussão. Neste sentido, a participação depende da vontade política dos governos locais e dos seus estilos de relação com a população (Borja, 2005), sendo difícil alcançar a coesão social quando o outro não se sente integrado no processo cívico (Medeiros et al., 2008). O desinteresse e comodismo por parte dos cidadãos é um facto assumido pelos próprios, falta avaliar o peso da falta de estímulo, divulgação e informação das entidades competentes, e ainda a falta de estratégia e clarificação relativa ao quando, como e onde se pode e deve participar. Por fim, a perceção, que não vamos aqui aprofundar, da valorização diferenciada da participação em função do perfil do cidadão.

Técnicos e políticos defendem que os cidadãos têm falta de cultura cívica e formação específica, perspetivando a cultura académica e técnica como o referente universal. Por outro lado, a participação não é suficiente, defendem os cidadãos, porque esta deve ser complementada com outras fontes de decisão. Resulta que os primeiros, obcecados pela visão tecnicista, esquecem-se de que a cultura académica e técnica é apenas uma entre muitas outras fontes de conhecimento. Ao que acresce os cidadãos a autorreferenciarem-se como inabilitados para participar, uma visão de subalternidade involuntária frequentemente presente nos grupos sociais desfavorecidos (Freire, 2009).

41 Importa pois clarificar do que falamos quando falamos de participação pública: a participação não implica decisão, mas sim a definição de parâmetros que conduzam à decisão. Cada visão e opinião é um contributo adicional para a promoção de decisões mais justas e concertadas. Cabe aos especialistas decidir, com base entre outros fatores dos inputs recebidos através da participação pública. Tendo presente que este estudo apenas nos pode lançar pistas para investigações futuras, mas que os resultados vão ao encontro das tendências internacionais de desinteresse e descredibilizada na 
democracia (Cabral et al., 2008) - resulta, no nosso entender, clara a necessidade de agir ativamente através da construção de uma sociedade civil mais interventiva e de estruturas políticas mais motivadas para a partilha de decisões com as comunidades visadas. Em modo de proposta defende-se a indispensabilidade de envolver os agentes, especialmente os decisores, numa estratégia alicerçada de "cima para baixo" que vise verdadeiramente "educar" quem tem o poder de influenciar e promover o debate. A capacitação de todos e todas, especialmente dos técnicos e políticos, como agentes privilegiados na mudança assume-se pois como a condição para o diálogo. Dar a voz aos cidadãos implica mais do que um direito teórico, plasmado na Constituição da República Portuguesa ou na diversa legislação em vigor, implica principalmente criar o espaço físico - de proximidade, equidade e transparência - onde a democracia deliberativa seja um processo dinâmico e de diálogo contínuo, com ou sem consenso, mas obrigatoriamente através do respeito das diferentes necessidades e aspirações de todos e todas. Até prova em contrário, a participação de todos e de todas continua a ser o instrumento privilegiado para construir cidades mais democráticas, equitativas e justas.

\section{BIBLIOGRAFIA}

ALVES, S. C. (2001). Planeamento Colaborativo em Contextos de Regeneração Urbana (Tese de Mestrado - FEUP), Porto.

ASCHER, F. ([2004] 2010). Novos princípios do urbanismo. Seguido de novos compromissos urbanos, um léxico, Lisboa, Livros Horizonte.

ARNSTEIN, S. R. (1969). “A Ladder of Citizen Participation”, JAIP, vol. 35, n.ํ 4, pp. 216-224.

BORJA, J. (2005). La ciudad conquistada, Madrid, Alianza Editorial.

BRETON, P. (2001). A palavra manipulada, Lisboa, Editorial Caminho.

CABRAL, M., F. Silva e T. Saraiva (orgs.) (2008). Cidadania \& Participação, Lisboa, Instituto de Ciências Sociais da Universidade de Lisboa.

FELT, U. (2000). “A adaptação do conhecimento cientifíco ao espaço público”. In M. Gonçalves (org.), Cultura Científica e Participação Pública, Oeiras, Celta Editora.

FERREIRA, J. (2003). Gestão democrática e participativa: um caminho para cidades socialmente mais justas? Em www.usp.br/fau/docentes/depprojeto/j_whitaker/ibase.doc

FREIRE, Paulo ([1968] 2009). Pedagogia do Oprimido. 48. a edição, São Paulo, Paz e Terra.

GONÇALVES, M. (2000). Cultura Científica e Participação Pública, Oeiras, Celta Editora.

GUERRA, I. (2006). Participação e Acção Colectiva: Interesses, Conflitos e Consensos, Estoril, Princípia Editora, Lda.

HEALEY, P. ([1997] 2006). Collaborative Planning: Shaping places in Fragmented Societies, EUA, Palgrave Macmillan. 
INNES, J. E. ([1989] 2002). Knowledge and Public Policy: The search for meaningful indicators, New Brunswick, Transaction Publishers.

INNES, J. e D. Booher (2004). “Reframing Public Participation for the 21st Century”, Planning Theory \& Practice, Vol. 5, No. 4, 419-436, Routlegde.

LIMA, M. (2000). Ciência e saber comum. In M. Gonçalves, Cultura Científica e Participação Pública, Oeiras, Celta Editora.

LOURENÇO, N., J. Craveiro e A. Antunes (1997). O ordenamento do território e a influência da participação pública nos processos de decisão. Final, Centro de Investigação Universidade Atlântica em parceria com o Grupo de Ecologia Social do LNEC e o Gabinete de Investigação e Sociologia Aplicada da Universidade Nova de Lisboa, Lisboa.

MATTOSO, J. (2008). A Identidade Nacional, 4. ed., Lisboa, Gradiva.

MEDEIROS, E. e M. Azevedo (2008). "Na cidade educativa, quem é o meu próximo?” In P. C. Pereira (org.), A Filosofia e a Cidade, Porto, Campo das Letras.

OLIVEIRA, L. (1996). Regionalização, Porto, Editora Asa.

PETTS, J. (2000). “Processos de Formação de Consensos na Gestão de Resíduos”. In M. Gonçalves, Cultura Ciêntifica e Participação Pública, Oeiras, Celta Editora, pp. 161-181.

QUIVY, R. e L. Campenhoudt (2005). Manual de Investigação em Ciências Sociais, Lisboa, Gradiva.

SILVA, F. (2002). Espaço Público em Habermas, Lisboa, Imprensa de Ciências Sociais.

\section{NOTAS}

1. O Programa Polis consistiu numa intervenção de âmbito territorial protagonizada pelo governo português e suportada financeiramente pelas autarquias locais, pela Administração Central e pela Comunidade Europeia.

2. Amostra constituída pela população total dos alunos que frequentavam o último ano do ensino secundário na Escola Inês de Castro, situada na zona de intervenção do Programa Polis. Estamos perante uma amostra não representativa mas com características relevantes para a nossa hipótese. Entende-se que os jovens estão num período formativo particularmente sensível, em que a apropriação do espaço é mais intensa. Sublinhe-se ainda o facto de a Constituição de a República Portuguesa estabelecer o direito de voto a partir dos 18 anos de idade - o que reforça a pertinência da auscultação desta faixa etária.

3. Corresponde à população total.

4. Observou-se um desconhecimento significativo do grupo de cidadãos relativamente ao Programa Polis (não obstante ser a área de residência dos inquiridos). Por essa razão optou-se por utilizar a cidade de Vila Nova de Gaia como pergunta-filtro.

5. N..$^{-}$Citações/NC = 86; Amostra/N = 67/Não resposta/NR = 1.

6. Foi usada a seguinte nomenclatura: cidadãos $-\mathrm{C}$; técnicos $-\mathrm{T}$; políticos $-\mathrm{P}$; masculino - M; feminino $-\mathrm{F}$.

7. $\mathrm{NC}=90 ; \mathrm{N}=88 ; \mathrm{NR}=0$.

8. $\mathrm{NC}=33 ; \mathrm{N}=64 ; \mathrm{NR}=0$.

9. $\mathrm{NC}=15 ; \mathrm{N}=50 ; \mathrm{NR}=2$. Esta resposta pode levar-nos a outras observações $-\mathrm{o}$ facto de a linguagem não ser entendida da mesma forma entre diferentes interluctores.

10. O que resulta da junção entre os que defendem não ser a participação dos cidadãos suficiente e os que simplesmente "não sabem".

11. $\mathrm{NC}=23 ; \mathrm{N}=28 ; \mathrm{NR}=6$. 
12. Questão colocada apenas ao grupo que responde "não ser suficiente a participação em Vila Nova de Gaia".

13. $\mathrm{NC}=64 ; \mathrm{N}=50 ; \mathrm{NR}=2$.

14. $\mathrm{NC}=80 ; \mathrm{N}=63 ; \mathrm{NR}=1$.

\section{RESUMOS}

As vantagens da participação pública e do envolvimento dos diversos atores nas decisões urbanísticas são largamente reconhecidas e defendidas pelas instituições governamentais e sociedade civil. Não obstante, a sua efetivação e impacto nas decisões urbanísticas em Portugal são relativamente escassos. Usou-se como estudo de caso um projeto de requalificação urbanística, o Programa Polis em Vila Nova de Gaia - Portugal. Questionaram-se homens e mulheres, políticos, técnicos e cidadãos sobre a importância da participação pública, exemplos desta, e estratégias de estímulo possíveis. Usaram-se simultaneamente metodologias qualitativas e quantitativas. Conclui-se que o conceito de participação pública é difuso e desconhecido a montante e a jusante do processo. Defende-se que a construção de uma política de participação pública efetiva envolve um processo de capacitação alargado a todos e todas e hierarquicamente transversal.

The benefits of public participation and community involvement are broadly recognised and encouraged by governmental institutions and civil society. However, its effectiveness and impact on Portuguese urban planning are relatively scarce. It was used as study case the urban project Polis Programme, in Vila Nova de Gaia - Portugal, and both qualitative and quantitative methodologies were used at the same time. Women and men, with different levels of decisionmaking, were asked about the importance of public participation, examples and strategies to improve it. The results highlight the notion of public participation as something diffuse and unknown, upstream and downstream of the process. The creation of a public participation policy needs to be support on the capacitation of everyone involved, men and women, crossing the hierarchy of decision.

\section{ÍNDICE}

Keywords: public participation, urban planning, city, public sphere

Palavras-chave: participação pública, planeamento urbano, cidade, esfera pública

\section{AUTOR \\ CECÍLIA DELGADO}

Universidade Lusíada (cmndelgado@gmail.com) 